\title{
An Update on Retinal Stem Cell Therapy
}

\author{
Jennifer R. Chao $\cdot$ Deepak A. Lamba
}

Published online: 19 July 2013

C Springer Science + Business Media New York 2013

\begin{abstract}
The use of stem cells will likely have a critical role to play in the coming years in regenerative medicine. The retina has been one of the earliest targets for stem cell derived replacement therapy due to easy access and the potential for direct monitoring of replacement cells. In this review, we will cover recent advances in differentiating human embryonic stem cells (hESC) into retinal cells, transplantation of hESC-derived retinal cells into animal models of retinal degeneration, and current human clinical trials involving subretinal transplantation these cells.
\end{abstract}

Keywords Human ES Cells - iPS cells · Retinal development - Transplantation - Clinical trials - RPE . Photoreceptors

\section{Introduction}

Retinal degenerative diseases such as retinitis pigmentosa or age-related macular degeneration affect $\sim 3$ million people in the United States. Glaucoma, a degeneration of the retinal ganglion cells, is the second leading cause of blindness in the world (after cataracts). At present, there are no commonly available treatments for patients suffering vision loss as a result of retinal cell death. In recent years, "microchip" prosthetic devices have restored some

\footnotetext{
J. R. Chao - D. A. Lamba

Department of Ophthalmology, University of Washington, Box 359608, 325 9th Avenue, Seattle, WA 98040, USA

e-mail: jrchao@uw.edu

D. A. Lamba ( $)$

Buck Institute for Research on Aging, 8001 Redwood Blvd, Novato, CA 94945, USA

e-mail:dlamba@buckinstitute.org
}

vision to blind patients [1, 2], indicating that while photoreceptors may be irreversibly damaged, retinal ganglion cells could be stimulated to create meaningful images. Other recent technologies have capitalized on this with the use of photochemicals to restore visual responses when photoreceptors have been lost in animal studies [3]. The prospect of actual cell replacement of lost photoreceptors and other cell types became truly feasible a few years ago when human embryonic stem cells (hESCs) and induced pluripotent stem cells could be successfully differentiated into all retinal cell types in culture, including photoreceptors, retinal ganglion cells, and retinal pigment epithelial (RPE) cells [4-10].

The retina is a particularly attractive target for stem cell therapy for a number of reasons. The retina is a surgically accessible tissue, and with the use of current vitreoretinal techniques, subretinal surgery through the vitreous cavity is widely accepted. In recent years, subretinal injections of adeno-associated viruses for Leber's congenital amaurosis gene therapy have been performed successfully [11-13]. The easy visualization of the retina also allows for a number of imaging modalities, such as fundus photography, ocular coherence tomography, and electrophysiological testing, to monitor the integration and function of transplanted hESC-derived retinal cells. Finally, results from the retina prosthetic chip imply that inner retinal cells retain their connectivity to the visual pathways in the brain such that replacement and integration of photoreceptors or RPE cells may be sufficient to restore or preserve vision.

In this review, we will discuss work in three major areas that has advanced the field forward in recent years. The first part of the review will discuss work from Yoshiki Sasai's lab on the three-dimensional morphogenesis of eyelike structures from mouse and human embryonic stem cells. Next, we will cover several recent papers addressing 
the possibility of retinal cell integration into a degenerating environment. In the final part of the review, we will focus on current clinical trials using stem cells for retinal repair.

\section{Embryonic Stem Cells to Model Early Development}

Tissue patterning during embryogenesis is dictated by both the morphogens in the microenvironment as well as direct intercellular interactions. Eye formation involves a complex process with multiple influences from surrounding tissues guiding the fates of the different cell types. Following eye-field specification, the neuroectoderm in the diencephalic region undergoes a series of steps to form the neural retina and the overlying retinal pigment epithelium. The earliest stage involves splitting of the eye fields secondary to signaling from the midline prechordal mesoderm [14-16]. Next, the regions extend outwards as diverticuli to form the optic vesicles (Fig. 1). This begins around days 21-23 post-conception in humans and embryonic day 8 in mice. The base of the diverticula undergoes constriction while the tip expands and comes in close proximity to the surface ectoderm. This induces a series of events such that the overlying ectoderm forms the lens placode while the neuroectoderm undergoes an invagination to form a bilayered structure. The inner layer further differentiates into neural retina while the outer layer, under the influence of the surrounding mesenchyme, forms the retinal pigment epithelium.

These dynamic changes have been mainly deduced using multi-time-point analyses of embryos. Embryonic stem cells have now been shown to be able to generate many if not all of the different cells in the body, including retinal cells. Most of this differentiation has been carried out in two-dimensional cultures. However, Yoshiki Sasai's group published two interesting papers in the last couple of years showing three-dimensional optic cup morphogenesis from both mouse and hESCs using time-lapse dynamic live confocal imaging [17•, 18•]. These landmark papers observed in real-time the morphogenetic events during ES cell differentiation. In the first paper, the group looked at retinogenesis in mouse ES cells in a 3D-culture setting. By culturing the mouse ES cells in low-attachment plates to assist in re-aggregation and then culturing in the presence of Matrigel to provide basement membrane support, the cells differentiated into anterior neural ectoderm. The group used the Rx-GFP reporter mouse ES cell line. Rx is one of the earliest genes expressed throughout the anterior neural plate and is expressed abundantly in the optic vesicles $[19,20]$. Tracking the GFP reporter, they found 30-70 \% induction. The GFP-expressing areas appeared around day 5 and started the process of evagination, which was complete by day 7 . Following this, the tips of the optic

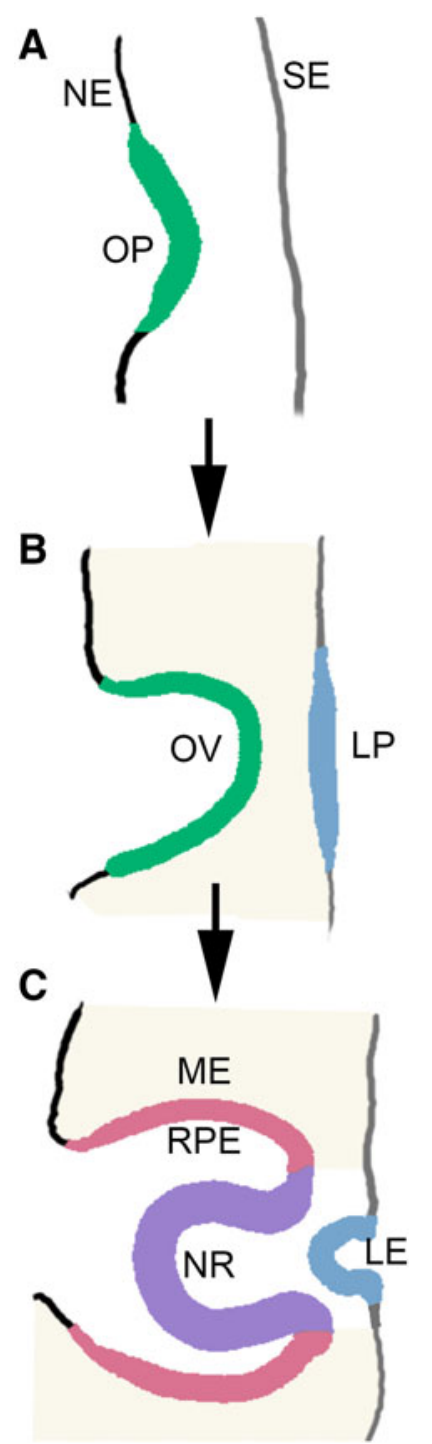

Fig. 1 Steps involved in eye morphogenesis. a Optic placode (OP) arises from the diencephalic neuro-ectoderm (NE). b The placode evaginated to form optic vesicle (OV) and the overlying surface ectoderm (SE) generates lens placode (LP). $\mathbf{c}$ The tip of optic vesicles invaginates to form a bilayered optic cup such that the outer layer forms retinal pigment epithelium (RPE) under the effect of the surrounding mesenchyme (ME), while the inner layer forms the neural retina (NR). The lens placode differentiates to form lens (LE)

placode-like structures started to indent, leading to invagination and formation of optic cup by day 9 . The authors found that microfilaments and the Rho-Rock pathway are central to invagination [21, 22]. Blocking the ROCK pathway using the small molecule inhibitor, Y27632, or myosin through blebbistatin abolished the formation of the optic cup at early stages of differentiation. Upon tracking the phosphorylation of myosin light chain 2 as a measure of acto-myosin activation, they found that specified neural retina loses this activity while staying high at the basal surface of the putative RPE. The other surprising finding 
here was that the lens/surface ectoderm was not necessary for the invagination process. Previous work from other groups had suggested that FGFs from the lens placode play a key role in neural retina specification at the tip of the outpouched optic placode as the two come in close proximity [23-25]. The data from this paper suggest that signals other than those from the lens may drive the neural retinal fate choice.

Further differentiation of the optic cells was tracked following manual mechanical excision of the Rx-GFP areas at day 7 and culturing under hyperoxic conditions (40\% oxygen) in the presence of taurine and all-trans retinoic acid. The neural retina cells underwent both differentiation and lamination over the next 20-25 days. The lamination was akin to the formation of three nuclear layers in the murine retina-the outer nuclear (photoreceptor), inner nuclear (interneurons), and ganglion cell layers. The cells differentiated to form all types of retinal neurons. They also found that the differentiated cells appeared in a specific time-dependent sequence with ganglion cells being the first and bipolar cells among the last cells to appear, consistent with what has been reported in vertebrate retinal development studies by various groups [26-28]. The data suggests that the mouse Rx-GFP cells can differentiate as in vivo and use the same cues present in the eye to generate the various types of retinal cells.

Following the initial report, the authors published another paper showing that similar processes occur in hESCs [18•]. To monitor differentiation, the group made a few human ES cell reporter lines. They knocked in a fluorescent reporter (Venus) in the Rx locus to track optic fate specification $[19,20]$ and into the Crx locus to track photoreceptor differentiation $[29,30]$. The retinal induction required a few modifications to the protocols. The cells required the use of a Wnt inhibitor, previously shown by our lab to promote retinal induction [4], as well as a ROCK pathway inhibitor to promote human ES cell survival following single-cell dissociation [31]. Additionally, as opposed to mouse cultures, serum and sonic hedgehog signaling were needed in their protocol for optimum optic tissue induction. Following this optic placode-like induction, RPE fate specification only occurred when media was supplemented with a small molecule Wnt- $\beta$-catenin activator CHIR99021. Wnt activation from the surrounding mesenchyme has previously been shown to be critical to RPE specification [32, 33]. Wnts directly regulate the expression of MITF and OTX2, two key genes involved in RPE specification [33]. Upon differentiation of human ES cells using the above protocol, Rx-GFP areas arose and underwent evagination followed by invagination of the tips to form the bilayered optic cups.

Upon further differentiation of the Rx-GFP areas, the manually dissected optic vesicle-like structures underwent lamination akin to the mouse ES cell cultures, although it took considerable time. Even though CRX expression appeared as early as day 34 , a complete outer nuclear layer and markers of mature photoreceptors required over 4 months in culture. Another important distinction was mal-lamination of at least a few photoreceptors, mainly rods, as far off as the ganglion cell layer. The human retinas and the corresponding human ES cell-derived optic vesicles are much larger than mouse and may require additional positional cues that could be missing in the in vitro cultures. However, there are also reports of similar, although far less frequent, mal-localization of photoreceptors during human fetal retinal development [34]. Inhibition of the Notch pathway has previously been shown to synchronize retinal differentiation in mouse and chicken retinas [35] as well as retinal cells from pluripotent stem cells $[8,36]$. The Sasai group used small molecule Notch pathway inhibitors to accelerate the differentiation of ES cells to the photoreceptor lineage as early as day 40 of culture. Finally, they showed that the differentiated structures can be cryopreserved using a two-step vitrification technique [18•]. The ability to generate more mature retinal cells and preserve them in a viable form for later use is critical to translating these findings into potentially cellbased therapies for patients. This work shows that both of these steps can be carried efficiently.

Similar laminated optic vesicle-like structures have been described by David Gamm's group as well [5, 37]. Their lab does not use specific inducers but instead allows cells to differentiate in a serum-free N2 supplement containing media. Regions with neural rosette-like morphology with bright ring peripheries were manually picked and cultured under low-attachment conditions. Over the course of 3 months, these regions took up retina-like morphology with distinct lamination. Unlike those from the Sasai group, photoreceptors in these hESC-derived retinal floating cultures did seem to laminate to the right layer. They could bias the fate decision to RPE by culturing the manually picked colonies with Activin A [38]. The protocol has been confirmed by other groups [39] and has been recently demonstrated to work under xeno-free culture conditions [40].

While promising, differentiation of the retinal stem cells generated using the described protocols has been tricky. Different groups have shown varying efficiencies using a variety of retinal cell makers. Ideally, we would like to synchronize the differentiation of all cells to a single fate, resulting in a pure population of either photoreceptor cells or retinal ganglion cells. A number of pathways have been suggested in the retinal developmental biology literature to promote these specific fates. Activation of cAMP [41] using 3-isobutyl-1-methylxanthine (IBMX) results in the loss of retinal progenitor characteristics and promotes photoreceptor differentiation in mouse retinas. Similarly, 
retinoic acid and taurine have been implicated in photoreceptor differentiation in murine retina and human retinal cultures [42-44]. Thyroid hormone (T3) has a cone-photoreceptor specific effect in rat retinal cultures [42]. However, while most of these compounds have been used for differentiation of mouse or human ESC or iPSC-derived retinal cells with little effect [8, 36, 45], as described above, inhibition of the Notch pathway seems to be effective in synchronizing differentiation and has been reproducibly used. Identification of methods to generate pure cultures free of any remaining stem cells will be the key to generating a safe and effective source of cells for cell-based therapies.

\section{Repair of Neural Retina Using Photoreceptors}

Robin Ali's group at UCL has been doing some pioneering work to better understand photoreceptor cell integration into the retina following subretinal injections. Their 2006 paper showed the most efficient integration of transplanted cells in a normal retina [46]. The authors used the Nrl-GFP mouse [47] to transplant labeled rod photoreceptors and track them following transplantation. These rod precursors are identified by expression of GFP under control of the promoter for $N R L$, a rod-specific transcription factor. They showed that for maximal integration, the transplanted cells needed to be very young and that as the photoreceptors mature, their integration capacity decreases dramatically. This work has since been confirmed by multiple labs around the world. Recent work out of Tom Reh's lab suggests that the poor integration of older photoreceptors is mainly due to poor survival of the older photoreceptors following dissociation rather than a loss of an inherent capacity to migrate and integrate due to maturation [48]. This suggests that identification of methods that improve adult photoreceptor survival may uncover another potential source of cells for effective subretinal transplantation.

A more recent report by Robin Ali's group describes subretinal injections of mouse $\mathrm{Nrl}-\mathrm{GFP}$ rod photoreceptor precursors into the subretinal space of $G N A T 1^{-/-}$mice, a murine model that lacks the rod $\alpha$-transducin and thus has no rod function [49]. A distinguishing feature of this study from earlier ones is that they transplant many more photoreceptors $(200,000 \mathrm{Nrl}-\mathrm{GFP}$ rod precursors) into both the superior and inferior retina than previous studies. Approximately 18,000 rod-precursors integrated, were located in the outer nuclear layer, formed classic triad synapses with endogenous horizontal and bipolar neurons, were light responsive with dimflash kinetics, and were capable of driving optokinetic head tracking and visually guided behavior in the $\mathrm{GNATI}^{-/-}$mice [49]. This and earlier studies assessed the success of photoreceptor transplantation in either wild-type animals or models of retinal degeneration at single time points [7, 46, 49-52]. Two recent studies examine the effects of specific models of degeneration and the extent of degeneration on transplanted photoreceptor integration and function $[53 \cdot, 54]$.

The UCL group published a very detailed paper looking into the differences in integration of rod photoreceptor transplantation across a number of mouse models of inherited photoreceptor degenerations [53•]. The different models chosen varied in their speed of degeneration, gliosis and status of the outer limiting membranes (OLMs). They found that in degeneration models that had progressive gliosis over time such as GNAT1 ${ }^{-1-}, \mathrm{Crb}^{-1-}$ and $\mathrm{Rho}^{-1-}$ mice, the potential for photoreceptor integration decreases over time as well. Disruption of the OLM may partially rescue this loss of integration. By using ZO-1 siRNA or Chondrotinase $\mathrm{ABC}$, both of which can disrupt the glial tight junctions at the OLM, they could increase the number of integrated cells in the $\mathrm{Rho}^{-1-}$ and the wild-type background, as has been previously reported by a number of groups.

Another publication looked at the integration of newborn photoreceptors in retinal degeneration mice with a mutation in the rod-specific cGMP phosphodiesterase $\beta 6$ subunit $\left(\mathrm{Pde}^{-1-} \mathrm{b}^{-1}, \mathrm{rd} 1\right)$ [54]. These mice undergo rapid rod photoreceptor degeneration as early as 10 days after birth, and there is total rod photoreceptor and outer nuclear layer loss by $3.5-4$ weeks. The authors showed that following transplantation of newborn (post-natal day 3) photoreceptors into 3-week-old RD1 mice, a newly developed outer nuclear layer of transplanted cells formed. However, since the host rod photoreceptors are completely lost by the time of analysis, it is difficult to confirm morphological integration, though the transplanted cells did express synaptophysin at their end feet. Unpublished work from our lab in both RD1 and AIPL1 ${ }^{-1-}$ mice using hESC-derived retinal cells revealed a similar presence of transplanted cells in the subretinal space, but it was difficult to confirm the extent of the functional integration as was seen in our work in $\mathrm{Crx}^{-1-}$ mice [7]. To assess functional integration, the group measured pupillary constriction, a behavioral test to compare time spent in a lighted cage, and cerebral blood flow. The mice that had undergone subretinal transplantation performed better in all three assays, suggesting functional improvement following injection. The nature of the assessment makes it difficult to assess whether the improvement was a direct effect of the transplanted cells or secondary to enhanced neuroprotection and function of the host cones in the presence of the transplanted rods, as has been shown in vitro [55].

There has also been significant interest in developing a cell replacement strategy for degenerating retinal ganglion cells (RGCs) seen in glaucoma. Retinal ganglion cells can 
be differentiated from human ESCs and iPSCs in protocols similar to those previously described for photoreceptors. Ideally, transplanted RGCs would integrate into the ganglion cell layer (GCL), extend axonal projections along the correct topographical route in the nerve fiber layer, and reach the correct targets in the brain through the optic nerve. While challenging, recent work has demonstrated the ability of primary mouse and in vitro differentiated RGCs to survive, migrate to the GCL, and extend neurites after intravitreal injection into the host mouse eye [56]. In another recent study, human Müller glia were differentiated into RGC precursors and transplanted on the inner retinal surface of Lister hooded rats that had been chemically depleted of RGCs [57]. Although the transplanted cells were observed to extend processes into the RGC layer, they did not extend long processes towards the optic nerve. Continuing work on RGC transplant studies holds significant promise for cell-based therapies for those suffering from glaucoma and perhaps other optic neuropathies as well.

Overall, while these animal studies appear promising, there are currently no ongoing clinical trials involving the subretinal transplantation of photoreceptors or retinal ganglion cells in human subjects. Some technical obstacles that remain to be addressed include the differentiation of photoreceptors in a xeno-free environment, differentiation of a large number of photoreceptors, maintaining photoreceptor viability through one or multiple freeze/thaw cycles, and maintaining cell viability during the course of the surgical procedure, given the more fragile nature of photoreceptors and retinal ganglion cells compared to RPE cells. Finally, although there are clues, it is not yet evident the level of host retinal degeneration that would be ideal for these transplantation studies. Nevertheless, many ongoing pre-clinical studies will help better define these parameters prior to the pursuit of a human clinical trial.

\section{Clinical Trials of Retinal Degenerative Diseases with Human Stem Cells}

\section{Retinal Pigment Epithelium}

RPE cells form a pigmented monolayer barrier between the photoreceptors and choroidal blood supply. RPE cells are polarized with apical microvilli for phagocytosis of photoreceptor outer segments, selectively transport ions, nutrients, and metabolic products, secrete cytokines, and play a critical role in the phototransduction cascade [58-60]. When the RPE is damaged or lost, as observed in patients affected by Lebers Congenital Amaurosis or age-related macular degeneration (AMD), the overlying neurosensory retina is compromised, and vision is impaired. The Royal College of
Surgeons (RCS) rat has classically served as the model of RPE degeneration due to a MERTK mutation that prevents RPE phagocytosis, resulting in photoreceptor cell loss over the course of several months $[61,62]$. Early studies transplanting either freshly isolated RPE cells or human RPE cell lines, such as ARPE-19, into the subretinal space of RCS rats demonstrated a delay of photoreceptor degeneration, improvements in electrophysiologic testing, and improvements in functional testing, such as optometry and visual acuity-dependent exploratory behavior [63-67]. More recently, human stem cell-derived RPE cells were transplanted into the subretinal space of RCS rats and similarly demonstrated significant visual improvement over untreated controls [68]. Potential mechanisms for this rescue include either diffusible neurotrophic factors produced by the transplanted hESC-derived RPE to the remaining neurosensory retina and by direct integration and cell replacement of the dysfunctional native counterparts. In the RCS animal model, some studies indicate that there is photoreceptor rescue beyond the subretinal transplant area while others indicate that cell contact is required for photoreceptor rescue [63, 66].

Based on these early studies demonstrating the beneficial effect of subretinal transplantation of human RPE, including human embryonic stem cell (hESC)-derived RPE cells and subsequent longer-term safety studies [68], the US Food and Drug Administration (FDA) granted approval for hESCderived RPE subretinal transplantation into human patients (Table 1). The two trials enrolled patients with Stargardt's dystrophy, primarily a photoreceptor disease that adversely affects RPE as a consequence, and patients with AMD, a degeneration affecting both the RPE and photoreceptors (registered with ClinicalTrials.gov, numbers NCT01345006 and NCT01344993, respectively). Preliminary results of the first hESC-derived RPE subretinal transplantation studies in humans were reported recently [69]. The RPE were differentiated from hESC line MA09, expanded, and cryopreserved at passage 2 for clinical use under Good Manufacturing Practices. In preclinical studies, the hESC-RPE cells were injected into the subretinal space of NIH III immune-nude mice for tumorigenicity and biodistribution safety studies, and ELOVL4 mice for efficacy studies [68]. One eye in each of two patients, one with Stargardt's dystrophy and the other with AMD, received a subretinal injection of $\sim 50,000$ viable hESC-RPE in a volume of $150 \mu \mathrm{l}$ into one preselected pericentral macular region. In order to increase the chances of hESC-RPE integration, optical coherence tomography (OCT) was used to determine an injection location where native RPE and neurosensory retina were not completely compromised. Four months after the surgery, neither of the two patients lost vision, and the authors indicate that there may have been a modest improvement in the vision in both patients. Both patients underwent an immunosuppression regimen of 
Table 1 Recent clinical trials using pluripotent stem cell derived cells or neural stem cells for juvenile and age-related Macular Degeneration

\begin{tabular}{|c|c|c|c|c|c|}
\hline Clinical trial name & $\begin{array}{l}\text { ClinicalTrials.gov } \\
\text { identifier }\end{array}$ & $\begin{array}{l}\text { Target } \\
\text { disease }\end{array}$ & Transplanted cell type & Sponsor & Status \\
\hline $\begin{array}{l}\text { Safety and tolerability of subretinal } \\
\text { transplantation of hESC-RPE cells in } \\
\text { patients with Stargardt's Macular Dystrophy }\end{array}$ & $\begin{array}{l}\text { NCT01469832 } \\
\text { NCT01345006 }\end{array}$ & $\begin{array}{l}\text { Stargardt's } \\
\text { Macular } \\
\text { Dystrophy }\end{array}$ & $\begin{array}{l}\text { hESC-derived RPE } \\
\text { cells }\end{array}$ & $\begin{array}{l}\text { Advanced } \\
\text { cell } \\
\text { technology }\end{array}$ & $\begin{array}{l}\text { Phase I/II, } \\
\text { Multi-Center } \\
\text { (US), } \\
\text { recruiting }\end{array}$ \\
\hline $\begin{array}{l}\text { Safety and toleratbility of subretinal } \\
\text { transplantation of hESC-derived RPE } \\
\text { (MA09-hRPE) cells in patients with } \\
\text { advanced dry age-related Macular } \\
\text { Degeneration (Dry AMD) }\end{array}$ & NCT01344993 & $\begin{array}{l}\text { Advanced } \\
\text { Dry AMD }\end{array}$ & $\begin{array}{l}\text { hESC (MA09)-derived } \\
\text { hRPE cells }\end{array}$ & $\begin{array}{l}\text { Advanced } \\
\text { cell } \\
\text { technology }\end{array}$ & $\begin{array}{l}\text { Phase I/II, } \\
\text { Multi-Center } \\
\text { (US), } \\
\text { recruiting }\end{array}$ \\
\hline $\begin{array}{l}\text { A Phase I/IIa, open-label, single-center } \\
\text { prospective study to determine the safety and } \\
\text { tolerability of subretinal transplantation of } \\
\text { hESC-dervied RPE (MA09-hRPE) cells in } \\
\text { patients with advanced dry age-related } \\
\text { Macular Degeneration (AMD) }\end{array}$ & NCT01674829 & $\begin{array}{l}\text { Advanced } \\
\text { Dry AMD }\end{array}$ & $\begin{array}{l}\text { hESC (MA09)-derived } \\
\text { hRPE cells }\end{array}$ & $\begin{array}{l}\text { CHA Bio \& } \\
\text { Diostech }\end{array}$ & $\begin{array}{l}\text { Phase I/IIa, } \\
\text { Single Center } \\
\text { (Korea), } \\
\text { recruiting }\end{array}$ \\
\hline $\begin{array}{l}\text { A Study of implantation of hESC-derived RPE } \\
\text { in subjects with acute wet age-related } \\
\text { Macular Degeneration and Recent Rapid } \\
\text { Vision Decline }\end{array}$ & NCT01691261 & $\begin{array}{l}\text { AMD with } \\
\text { recent rapid } \\
\text { vision } \\
\text { decline }\end{array}$ & $\begin{array}{l}\text { hESC-derived RPE } \\
\text { monolayer on a } \\
6 \mathrm{~mm} \times 3 \mathrm{~mm} \\
\text { polyester membrane }\end{array}$ & Pfizer & $\begin{array}{l}\text { Phase I (US), } \\
\text { not yet } \\
\text { recruiting }\end{array}$ \\
\hline $\begin{array}{l}\text { Study of human central nervous system stem } \\
\text { cells (HuCNS-SC) in age-related Macular } \\
\text { Degeneration (AMD) }\end{array}$ & NCT01632527 & $\begin{array}{l}\text { AMD with } \\
\text { geographic } \\
\text { atrophy }\end{array}$ & HuCNS-SC cells & $\begin{array}{l}\text { StemCells, } \\
\text { Inc. }\end{array}$ & $\begin{array}{l}\text { Phase I/II, } \\
\text { Multi Center } \\
\text { (US), } \\
\text { recruiting }\end{array}$ \\
\hline Takahashi Clinical Study & TBA & Severe AMD & $\begin{array}{l}\text { iPSC-derived retinal } \\
\text { cells }\end{array}$ & RIKEN & $\begin{array}{l}\text { Clinical Study } \\
\text { (Japan), est. } \\
\text { recruiting } \\
\text { Sept } 2013\end{array}$ \\
\hline
\end{tabular}

tracrolimus and myocophenolate mofetil, the former for 6 weeks and the latter for 3 months. Given the limitations to studying human retina histology in a clinical setting, it is difficult to assess the extent of hESC-derived RPE engraftment in these eyes. However, encouragingly, there did not appear to be signs of gross RPE hyperproliferation, tumorigenicity, or immune-mediated transplant rejection at 4 months.

Despite the lack of obvious inflammation in these eyes, there are other safety concerns to this procedure that can be derived from the longer-term results of the three independent RPE65 gene replacement studies. These studies delivered adeno-associated viruses (AAV) into the subretinal space of patients with Lebers Congenital Amaurosis (LCAII) [11, 13, 70, 71]. AAV vectors were introduced into the subretinal space through an intravitreal approach similar to that described in the recent hESC-derived RPE study [69]. Follow-up studies reported the occurrence of a full thickness macular hole [13, 72], foveal thinning [71], secondary retinal detachment and choroidal effusions [73]. While the retinal detachment in the AAV study was successfully repaired, it is possible that cell-based therapies may complicate any rhegmatogenous retinal detachment that may develop. Proliferation of hESCderived RPE cells in the vitreous cavity may lead to an increased probability or severity of proliferative vitreoretinopathy, complicating the retinal detachment. In cases where a secondary retinal detachment does not develop, epiretinal membranes may develop from the reflux of hESC-derived RPE cells into the vitreous cavity. The field will gain greater insight into the safety of cell-based therapy delivered in an intravitreal fashion as the long-term results become available in these studies.

These is some concern that injection of RPE cells in suspension may not lead to proper integration due to the lack of orientation and monolayer structure as well as an unhealthy Bruch's membrane upon which to attach [74-76]. In addition, it has been proposed that RPE cells injected in suspension have higher immunogenicity than those delivered as intact sheets and that they may not demonstrate full differentiation [77-79]. As a result, multiple groups have experimented with growing RPE cells on various substrates for subretinal transplantation with good success [80-82]. A Phase I study has been registered with ClinicalTrials.gov for implantation of hESC-derived RPE in subjects with acute neovascular AMD and rapid vision loss (Table 1). Instead of injecting hESCderived RPE cells in suspension as in the earlier trial, these RPE cells are immobilized on a polyester membrane $\left(17 \mathrm{~mm}^{2}\right.$ 
in size) in a monolayer for subretinal transplantation. This study is ongoing and no findings have been published to date (ClinicalTrials.gov, number NCT01691261). Another study is also being conducted using RPE cells grown on a biodegradable substrate for subretinal transplantation, although no results have been published to date. Even if these initial trials are not successful in bringing about visual recovery, results from these trials are crucial in providing us with data on the survival, integration and immunogenicity of the transplanted cells. These results will likely guide future cell transplant studies for photoreceptor, RGC, and RPE degenerative diseases.

\section{Other Cells for Subretinal Transplantation}

Non-retinal cells are also being transplanted into the subretinal space of patients with retinal disease. Human central nervous system stem cells (HuCNS-SC cells) were shown to be neuroprotective in a lysosomal storage disease mouse model with neurological disease [83]. In the retina, preclinical studies demonstrated that injection of HuCNS-SC cells in the subretinal space of RCS rats delayed host photoreceptor degeneration and resulted in cone density remaining relatively stable over a period of several months. The transplanted cells migrated radially in the host retina, maintained an immature phenotype, and did not exhibit signs of proliferation or tumorigenicity [84]. Based on these data, a clinical trial is currently recruiting patients with AMD and geographic atrophy (large regions of RPE cell loss) for subretinal injections of human central nervous system stem cells (HuCNS-SC) (ClinicalTrials.gov, number NCT01632527, Table 1).

Finally, Masayo Takahashi's group in Japan is reportedly taking on the ambitious project of transplanting induced pluripotent stem cell (iPSC)-derived retinal cells into patients with advanced AMD [85]. They plan to generate iPSCs from patient skin biopsies (fibroblasts), differentiate them into retinal cells, and transplant these cells into the subretinal space of the same patients. The expectation is that these patient-specific iPSC-derived cells would not provoke an immune response, as the donor and host cells are from the same individual [86]. Although there are fewer concerns regarding a host immune response, there is some concern regarding the tumorigenicity of iPSC-derived retinal cells. If this clinical study is approved by all of the appropriate regulatory agencies, patient enrollment is expected to begin as early as September 2013.

\section{Conclusion}

In this review, we have covered some recent advances in both basic and clinical research involving the use of stem cells and their progeny for retinal repair. These and other similar studies have been incrementally providing data that will eventually allow us to treat and repair vision in patients with retinal degenerative disorders.

Disclosure Jennifer R. Chao and Deepak A. Lamba declare that they have no conflict of interest.

Compliance of Ethical Requirements This article does not contain any studies with human or animal subjects performed by any of the authors.

\section{References}

Papers of particular interest, published recently, have been highlighted as:

- Of importance

1. Humayun MS, et al. Visual perception in a blind subject with a chronic microelectronic retinal prosthesis. Vision Res. 2003;43(24): 2573-81.

2. Yanai $\mathrm{D}$, et al. Visual performance using a retinal prosthesis in three subjects with retinitis pigmentosa. Am J Ophthalmol. 2007;143(5):820-7.

3. Polosukhina A, et al. Photochemical restoration of visual responses in blind mice. Neuron. 2012;75(2):271-82.

4. Lamba DA, et al. Efficient generation of retinal progenitor cells from human embryonic stem cells. Proc Natl Acad Sci USA. 2006;103(34):12769-74.

5. Meyer JS, et al. Modeling early retinal development with human embryonic and induced pluripotent stem cells. Proc Natl Acad Sci USA. 2009;106(39):16698-703.

6. Osakada F, et al. Toward the generation of rod and cone photoreceptors from mouse, monkey and human embryonic stem cells. Nat Biotechnol. 2008;26(2):215-24.

7. Lamba DA, Gust J, Reh TA. Transplantation of human embryonic stem cell-derived photoreceptors restores some visual function in Crx-deficient mice. Cell Stem Cell. 2009;4(1):73-9.

8. Osakada $\mathrm{F}$, et al. In vitro differentiation of retinal cells from human pluripotent stem cells by small-molecule induction. J Cell Sci. 2009;122(Pt 17):3169-79.

9. Phillips MJ, et al. Blood-derived human iPS cells generate optic vesicle-like structures with the capacity to form retinal laminae and develop synapses. Invest Ophthalmol Vis Sci. 2012;53(4):2007-19.

10. Hambright D, et al. Long-term survival and differentiation of retinal neurons derived from human embryonic stem cell lines in un-immunosuppressed mouse retina. Mol Vis. 2012;18:920-36.

11. Bainbridge JW, et al. Effect of gene therapy on visual function in Leber's congenital amaurosis. N Engl J Med. 2008;358(21): 2231-9.

12. Cideciyan AV, et al. Vision 1 year after gene therapy for Leber's congenital amaurosis. N Engl J Med. 2009;361(7):725-7.

13. Maguire AM, et al. Safety and efficacy of gene transfer for Leber's congenital amaurosis. N Engl J Med. 2008;358(21): 2240-8.

14. Li H, et al. A single morphogenetic field gives rise to two retina primordia under the influence of the prechordal plate. Development. 1997;124(3):603-15.

15. Pera EM, Kessel M. Patterning of the chick forebrain anlage by the prechordal plate. Development. 1997;124(20):4153-62. 
16. Chiang $\mathrm{C}$, et al. Cyclopia and defective axial patterning in mice lacking Sonic hedgehog gene function. Nature. 1996;383 (6599):407-13.

17. - Eiraku M, et al. Self-organizing optic-cup morphogenesis in three-dimensional culture. Nature. 2011;472(7341):51-6. The paper showed the real-time in vitro optic cup generation from mouse ES cells.

18. - Nakano T, et al. Self-formation of optic cups and storable stratified neural retina from human ESCs. Cell Stem Cell. 2012;10(6):771-85. This paper highlights the steps of optic vesicle and cup formation from human ES cells as well as their ability to be cryopreserved.

19. Furukawa T, Kozak CA, Cepko CL. Rax, a novel paired-type homeobox gene, shows expression in the anterior neural fold and developing retina. Proc Natl Acad Sci USA. 1997;94(7):3088-93.

20. Mathers PH, et al. The Rx homeobox gene is essential for vertebrate eye development. Nature. 1997;387(6633):603-7.

21. Zimmerman SG, et al. Apical constriction and invagination downstream of the canonical Wnt signaling pathway require Rho1 and Myosin II. Dev Biol. 2010;340(1):54-66.

22. Sawyer JM, et al. Apical constriction: a cell shape change that can drive morphogenesis. Dev Biol. 2010;341(1):5-19.

23. McAvoy JW. Cytoplasmic processes interconnect lens placode and optic vesicle during eye morphogenesis. Exp Eye Res. 1980;31(5):527-34.

24. Hyer J, Mima T, Mikawa T. FGF1 patterns the optic vesicle by directing the placement of the neural retina domain. Development. 1998;125(5):869-77.

25. Pittack C, Grunwald GB, Reh TA. Fibroblast growth factors are necessary for neural retina but not pigmented epithelium differentiation in chick embryos. Development. 1997;124(4):805-16.

26. Sidman RL. Histogenesis of the mouse retina. Studies with [3H] thymidine. In: Smelser GK, editor. The structure of the eye. New York: Academic Press; 1961.

27. Reh TA, Cagan RL. Intrinsic and extrinsic signals in the developing vertebrate and fly eyes: viewing vertebrate and invertebrate eyes in the same light. Perspect Dev Neurobiol. 1994;2(2):183-90.

28. Cepko CL, et al. Cell fate determination in the vertebrate retina. Proc Natl Acad Sci USA. 1996;93(2):589-95.

29. Chen S, et al. Crx, a novel Otx-like paired-homeodomain protein, binds to and transactivates photoreceptor cell-specific genes. Neuron. 1997;19(5):1017-30.

30. Furukawa T, Morrow EM, Cepko CL. Crx, a novel otx-like homeobox gene, shows photoreceptor-specific expression and regulates photoreceptor differentiation. Cell. 1997;91(4):531-41.

31. Watanabe $\mathrm{K}$, et al. A ROCK inhibitor permits survival of dissociated human embryonic stem cells. Nat Biotechnol. 2007; 25(6):681-6.

32. Fujimura N, et al. Spatial and temporal regulation of Wnt/betacatenin signaling is essential for development of the retinal pigment epithelium. Dev Biol. 2009;334(1):31-45.

33. Westenskow P, Piccolo S, Fuhrmann S. Beta-catenin controls differentiation of the retinal pigment epithelium in the mouse optic cup by regulating Mitf and Otx2 expression. Development. 2009;136(15):2505-10.

34. Hendrickson A, et al. Rod photoreceptor differentiation in fetal and infant human retina. Exp Eye Res. 2008;87(5):415-26.

35. Nelson BR, et al. Transient inactivation of Notch signaling synchronizes differentiation of neural progenitor cells. Dev Biol. 2007;304(2):479-98.

36. Tucker BA, et al. Transplantation of adult mouse iPS cell-derived photoreceptor precursors restores retinal structure and function in degenerative mice. PLoS One. 2011;6(4):e18992.

37. Meyer JS, et al. Optic vesicle-like structures derived from human pluripotent stem cells facilitate a customized approach to retinal disease treatment. Stem Cells. 2011;29(8):1206-18.
38. Fuhrmann S, Levine EM, Reh TA. Extraocular mesenchyme patterns the optic vesicle during early eye development in the embryonic chick. Development. 2000;127(21):4599-609.

39. Zhu Y, et al. Three-dimensional neuroepithelial culture from human embryonic stem cells and its use for quantitative conversion to retinal pigment epithelium. PLoS One. 2013;8(1):e54552.

40. Sridhar A, Steward MM, Meyer JS. Nonxenogeneic growth and retinal differentiation of human induced pluripotent stem cells. Stem Cells Transl Med. 2013;2(4):255-64.

41. Taylor M, Reh TA. Induction of differentiation of rat retinal, germinal, neuroepithelial cells by dbcAMP. J Neurobiol. 1990; 21(3):470-81.

42. Kelley MW, Turner JK, Reh TA. Ligands of steroid/thyroid receptors induce cone photoreceptors in vertebrate retina. Development. 1995; 121(11):3777-85.

43. Altshuler $D$, et al. Taurine promotes the differentiation of a vertebrate retinal cell type in vitro. Development. 1993;119(4): 1317-28.

44. Kelley MW, Turner JK, Reh TA. Retinoic acid promotes differentiation of photoreceptors in vitro. Development. 1994; 120(8):2091-102.

45. Mellough CB, et al. Efficient stage-specific differentiation of human pluripotent stem cells toward retinal photoreceptor cells. Stem Cells. 2012;30(4):673-86.

46. MacLaren RE, et al. Retinal repair by transplantation of photoreceptor precursors. Nature. 2006;444(7116):203-7.

47. Akimoto M, et al. Targeting of GFP to newborn rods by Nrl promoter and temporal expression profiling of flow-sorted photoreceptors. Proc Natl Acad Sci USA. 2006;103(10):3890-5.

48. Gust J, Reh TA. Adult donor rod photoreceptors integrate into the mature mouse retina. Invest Ophthalmol Vis Sci. 2011;52(8):5266-72.

49. Pearson RA, et al. Restoration of vision after transplantation of photoreceptors. Nature. 2012;485(7396):99-103.

50. Lakowski J, et al. Cone and rod photoreceptor transplantation in models of the childhood retinopathy Leber congenital amaurosis using flow-sorted Crx-positive donor cells. Hum Mol Genet. 2010;19(23):4545-59.

51. Pearson RA, et al. Targeted disruption of outer limiting membrane junctional proteins (Crb1 and ZO-1) increases integration of transplanted photoreceptor precursors into the adult wild-type and degenerating retina. Cell Transplant. 2010;19(4):487-503.

52. Singhal S, et al. Chondroitin sulfate proteoglycans and microglia prevent migration and integration of grafted Muller stem cells into degenerating retina. Stem Cells. 2008;26(4):1074-82.

53. - Barber AC, et al. Repair of the degenerate retina by photoreceptor transplantation. Proc Natl Acad Sci USA. 2013;110(1): 354-9. The recent report compares integration of young photoreceptors in various models of retinal degeneration to understand the effects of rate of degeneration, gliotic status of the host and the intactness of OLM.

54. Singh MS, et al. Reversal of end-stage retinal degeneration and restoration of visual function by photoreceptor transplantation. Proc Natl Acad Sci USA. 2013;110(3):1101-6.

55. Fintz AC, et al. Partial characterization of retina-derived cone neuroprotection in two culture models of photoreceptor degeneration. Invest Ophthalmol Vis Sci. 2003;44(2):818-25.

56. Hertz J, et al. Survival and Integration of Developing and Progenitor-Derived Retinal Ganglion Cells Following Transplantation. Cell Transplant. 2013 (in press).

57. Singhal S, et al. Human Muller glia with stem cell characteristics differentiate into retinal ganglion cell (RGC) precursors in vitro and partially restore RGC function in vivo following transplantation. Stem Cells Transl Med. 2012;1(3):188-99.

58. Shi G, et al. Control of chemokine gradients by the retinal pigment epithelium. Invest Ophthalmol Vis Sci. 2008;49(10): $4620-30$. 
59. Sparrow JR, Hicks D, Hamel CP. The retinal pigment epithelium in health and disease. Curr Mol Med. 2010;10(9):802-23.

60. Strauss $O$. The retinal pigment epithelium in visual function. Physiol Rev. 2005;85(3):845-81.

61. D'Cruz PM, et al. Mutation of the receptor tyrosine kinase gene Mertk in the retinal dystrophic RCS rat. Hum Mol Genet. 2000;9(4):645-51.

62. Mullen RJ, LaVail MM. Inherited retinal dystrophy: primary defect in pigment epithelium determined with experimental rat chimeras. Science. 1976;192(4241):799-801.

63. Lavail MM, et al. Retinal pigment epithelial cell transplantation in RCS rats: normal metabolism in rescued photoreceptors. Exp Eye Res. 1992;55(4):555-62.

64. Lund RD, et al. Subretinal transplantation of genetically modified human cell lines attenuates loss of visual function in dystrophic rats. Proc Natl Acad Sci USA. 2001;98(17):9942-7.

65. Pinilla I, et al. Preservation of outer retina and its synaptic connectivity following subretinal injections of human RPE cells in the Royal College of Surgeons rat. Exp Eye Res. 2007;85(3):381-92.

66. Sauve Y, et al. Preservation of visual responsiveness in the superior colliculus of RCS rats after retinal pigment epithelium cell transplantation. Neuroscience. 2002;114(2):389-401.

67. Whiteley SJ, et al. Improvement of the pupillary light reflex of Royal College of Surgeons rats following RPE cell grafts. Exp Neurol. 1996;140(1):100-4.

68. Lu B, et al. Long-term safety and function of RPE from human embryonic stem cells in preclinical models of macular degeneration. Stem Cells. 2009;27(9):2126-35.

69. Schwartz SD, et al. Embryonic stem cell trials for macular degeneration: a preliminary report. Lancet. 2012;379(9817):713-20.

70. Cideciyan AV, et al. Human gene therapy for RPE65 isomerase deficiency activates the retinoid cycle of vision but with slow rod kinetics. Proc Natl Acad Sci USA. 2008;105(39):15112-7.

71. Hauswirth WW, et al. Treatment of leber congenital amaurosis due to RPE65 mutations by ocular subretinal injection of adenoassociated virus gene vector: short-term results of a phase I trial. Hum Gene Ther. 2008;19(10):979-90.

72. Simonelli F, et al. Gene therapy for Leber's congenital amaurosis is safe and effective through 1.5 years after vector administration. Mol Ther. 2010;18(3):643-50.
73. Jacobson SG, et al. Gene therapy for leber congenital amaurosis caused by RPE65 mutations: safety and efficacy in 15 children and adults followed up to 3 years. Arch Ophthalmol. 2012;130(1): 9-24.

74. Durlu YK, Tamai M. Transplantation of retinal pigment epithelium using viable cryopreserved cells. Cell Transplant. 1997; 6(2):149-62.

75. Ho TC, Del Priore LV. Reattachment of cultured human retinal pigment epithelium to extracellular matrix and human Bruch's membrane. Invest Ophthalmol Vis Sci. 1997;38(6):1110-8.

76. Lu JT, et al. Thin collagen film scaffolds for retinal epithelial cell culture. Biomaterials. 2007;28(8):1486-94.

77. Ong JM, da Cruz L. A review and update on the current status of stem cell therapy and the retina. Br Med Bull. 2012;102:133-46.

78. Sheridan C, Williams R, Grierson I. Basement membranes and artificial substrates in cell transplantation. Graefes Arch Clin Exp Ophthalmol. 2004;242(1):68-75.

79. Streilein JW, et al. Immunobiology and privilege of neuronal retina and pigment epithelium transplants. Vision Res. 2002;42(4): 487-95.

80. $\mathrm{Hu} \mathrm{Y}$, et al. A novel approach for subretinal implantation of ultrathin substrates containing stem cell-derived retinal pigment epithelium monolayer. Ophthalmic Res. 2012;48(4):186-91.

81. Leng T, Fishman HA. Carbon nanotube bucky paper as an artificial support membrane for retinal cell transplantation. Ophthalmic Surg Lasers Imaging. 2013;44(1):73-6.

82. $\mathrm{Lu} \mathrm{B}$, et al. Mesh-supported submicron parylene-C membranes for culturing retinal pigment epithelial cells. Biomed Microdevices. 2012;14(4):659-67.

83. Tamaki SJ, et al. Neuroprotection of host cells by human central nervous system stem cells in a mouse model of infantile neuronal ceroid lipofuscinosis. Cell Stem Cell. 2009;5(3):310-9.

84. McGill TJ, et al. Transplantation of human central nervous system stem cells-neuroprotection in retinal degeneration. Eur J Neurosci. 2012;35(3):468-77.

85. Cyranoski D. Stem cells cruise to clinic. Nature. 2013;494(7438): 413.

86. Araki R, et al. Negligible immunogenicity of terminally differentiated cells derived from induced pluripotent or embryonic stem cells. Nature. 2013;494(7435):100-4. 